\title{
Psychological and behavioral disease during developmental age: the importance of the alliance with parents
}

This article was published in the following Dove Press journal:

Neuropsychiatric Disease and Treatment

21 October 2009

Number of times this article has been viewed

\author{
Michela Gatta' \\ Elisabetta Ramaglioni ${ }^{3}$ \\ Jessica Lai ${ }^{3}$ \\ Lorenza Svanellini ${ }^{3}$ \\ Irene Toldo' \\ Lara Del Col ${ }^{3}$ \\ Cinzia Salviato ${ }^{3}$ \\ Andrea Spoto ${ }^{2}$ \\ Battistella Pier Antonio 3 \\ 'Paediatrics Department, ${ }^{2}$ Department \\ of General Psychology, University of \\ Padua, Padua, Italy; ${ }^{3}$ Neuropsychiatric \\ Unit for Children and Adolescents, \\ Azienda ULSS I6, Padua, Italy
}

Correspondence: Michela Gatta Pediatrics Department, University of Padua, via Giustiniani 2, 35100

Padua, Italy

Email michela.gatta@unipd.it

\begin{abstract}
The aim of the study is to analyze the clinician's alliance with parents during the diagnostic process in relation to therapeutic compliance and clinical evolution of individuals aged $0-11$ years. The sample was formed by 84 individuals aged 0 to 11 years $(18<6$ years, 66 aged 6 to 11 years; 62 males and 22 females) who came to the Neuropsychiatric Unit for Children and Adolescents for a consultation regarding psychorelational and behavioral problems. Neuropsychiatric consultation took place in five diagnostic interviews with child and parents, separately. The last session was devoted to communication of psychiatric diagnosis (according to ICD 10) and therapeutic suggestions, if any. The clinician's relationship with parents and patients' participation were evaluated in terms of collaboration and quality of interaction, on the basis of pre-established criteria. Data about patients' therapeutic compliance and clinical outcome were collected during a follow-up visit eight months after the last session. Results suggest that the better the alliance between parents and clinician, the higher the therapeutic compliance and the likelihood of a positive outcome for patients. Our data suggest that good communication with parents benefits child patients, both in terms of response to the parents' need to report their children's worrying behavior and as a response to the discomfort expressed by children when they come in for consultation.
\end{abstract}

Keywords: psychopathology, developmental age, psychotherapy, alliance relationship, parental function

\section{Background}

It is difficult to separate psychodiagnostic activities and psychotherapy or its preliminary stages in the case of children and adolescent patients: at the same time as parents are requested to remember their child's story, they can actually become aware of individual and family history of a symptom, through appropriate connections and observations. ${ }^{1}$ Whether the psychodiagnostic process concludes without recommending psychotherapy or some form of intervention is suggested, the clinician's alliance with parents offers an important key to reading the situation. If, as Winnicot ${ }^{2}$ underlines, it is impossible to think of a baby without his or her mother close to $\mathrm{him} /$ her, it is equally impossible to think of working with children without including a relationship with their parents. ${ }^{3}$

Parents' collaboration and presence, especially during the diagnostic phase, are important to understand both the significance of symptoms and to what extent the child suffers in their existing environment where he or she has contacts (family, school, peer group, etc). The symptoms expressed by the child is rarely of his or her own only, but is linked with his or her relationship with caregivers. Therefore, there is a tendency 
to involve parents in both the diagnostic and therapeutic processes. Mancini notes that "alliance with parents, as well as with the child, is the essential requirement for therapy, therefore it must always be preserved."4

\section{Hypothesis}

The aim of the study is to analyze the alliance with parents during the diagnostic process in relation to therapeutic compliance and clinical evolution of individuals aged 0-11 years with psychorelational and behavioral problems. Our hypothesis is that the alliance between clinician and parents influences the therapeutic compliance of young patients and their clinical outcome.

\section{Methodology \\ Sample}

The sample was made up of male and female individuals aged 0 to 11 years, who came to the outpatients' neuropsychiatric service from January to December 2007. Patients with known organic pathology or who were pharmacologically treated were excluded from the sample. Out of 137 cases, 101 finished the diagnostic process. Eighty-four came to the neuropsychiatric clinic for a control visit eight months later. Among them, 16 did not receive suggestions for any treatment, while 68 were suggested to undergo psychotherapy. Therefore, the final sample included 84 individuals aged 0 to 11 years $(18<6$ years, 66 aged 6 to 11 years; 62 males and 22 females). Patients contacted the service in two ways: $33.3 \%$ came spontaneously while $66.7 \%$ came by referral (general practitioner, social services, other public services, or hospitals). The cultural level of the family, evaluated on the basis of parents' educational level, was low in $45.7 \%$, intermediate in $35.7 \%$, and high in $18 \%$ of cases. Six percent of the sample had parents with mental or physical disease and $9.5 \%$ of parents were divorced. At the end of the diagnostic process, we divided the sample into four categories on the basis of psychiatric diagnosis: 6\% were free of mental diseases according to the International Statistical Classification of Diseases and Related Health Problems (ICD-10) classification; $36.9 \%$ of them were classified as suffering from affective disorder (anxiety or mood disorders, F30-39 and F40-48); $40.5 \%$ had behavioral problems (F90-98); while 16.7\% had generalized developmental disorder F80-89). ${ }^{5}$

\section{Procedure}

During the first telephone contact with the service, an information sheet was filled in to collect data about the kind of request, how long the problem had been present, and who had suggested neuropsychiatric consultation.

Neuropsychiatric consultation took place in five diagnostic interviews with child and parents, separately. The last session was devoted to the communication of psychiatric diagnosis and therapeutic suggestions, if any. The psychiatric diagnosis was formulated according to ICD $10 .^{5}$

An anamnesis sheet collecting data about child's identification, his/her family, psychosocial situation, and clinical elements was filled in for each subject.

The clinican's alliance with parents was evaluated in terms of collaboration on the basis of the following criteria:

1. Consultation request

a. Spontaneous request and phone call by a parent (2)

b. Request on the basis on referral and phone call by a parent (1)

c. Request on the basis on referral and phone call by others (0)

2. Session attendance

a. Presence in all sessions (2)

b. Unattended session with justification and prior notice (1)

c. Unattended session without justification and without prior notice $(0)$

3. Presence of the parental couple

a. Both parents took part in the diagnostic process (2)

b. Parents took it in turns to take part in the diagnostic process (1)

c. Only one parent took part in the diagnostic process (0)

4. Cooperation during sessions

a. Parents talked about themselves and family dynamics and filled in tests (2)

b. Parents talked about themselves but refused to fill in any test or vice versa (1)

c. Parents refused to talk about themselves and to fill in tests (0)

5. Sharing and confrontation about diagnostic-therapeutic indications

a. Parents accepted and shared therapist's indications (2)

b. Parents were ambivalent towards therapist's indications (1)

c. Parents were oppositional and rejected therapist's indications (2)

Score: $7-10 \quad$ Collaborative parents

4-6 Partially collaborative parents

0-3 Uncollaborative parents.

The child's participation mode was evaluated during the diagnostic process by a neutral observer, by considering 
certain qualities of his or her relationship with the specialist and filling in four items:

1. General attitude towards the psychological consultation: active (a), passive (b), ambivalent or oppositional (c);

2. Mode of talking about his or her self and of tackling tests: active (a), passive (b), ambivalent or oppositional (c);

3. Recognition of existence of an internal or emotional disease: present (a), indifferent (b), refused (c);

4. Attitude towards the therapist: trust (a), indifference (b), distrust (c).

Therefore, the patient's participation mode was classified as follows: active (prevalence of a), passive (prevalence of $b$ ), ambivalent or oppositional (prevalence of c).

If two modes had been present with the same frequency of answers, the more conservative profile would have been chosen, but no such case actually occurred.

Data about patient's therapeutic compliance and clinical outcome were collected during a follow-up clinic visit eight months after the last session. They are based both on what was referred by patients about their subjective perception of health state and on symptomatology changes verified by the therapist over an eight-month period. Item 2 of clinical global impressions (CGI) - which refers to global improvement - was filled in for each patient: he or she was considered improved when the score was $1-2$, unchanged when the score was 3-5, and orse when the score was 6-7.

The following main variables were analyzed: patient participation, alliance with parents, clinical diagnosis (ICD 10), therapeutic compliance, and clinical evolution.

\section{Statistical analysis}

Data are expressed as frequency and variables are expressed in nominal and ordinal scale. The statistical significance of value difference has been evaluated using the Chi-squared test with a significance level of 0.05 . The correlation values have been evaluated using the Spearman's rho coefficient with a significance level of 0.05 . The analysis was performed with SPSS (v. 14 SPSS Inc, Chicago, IL, USA) software.

\section{Results}

Tables 1 and 2 present the frequencies of different variables as "Compliance" and "Clinical evolution", cross-tabled at different levels of the variable "Alliance with parents."

Results seem to confirm our initial hypothesis. We hypothesized that the better the alliance between parents and clinician, the higher the therapeutic compliance and the likelihood of positive clinical evolution of the patients. Chi-squared statistics supported these hypotheses: there is
Table I Frequencies table of the variable "Patient compliance" cross-tabled with the variable "Alliance with parents"

\begin{tabular}{llllll}
\hline & & \multicolumn{4}{l}{ Patient compliance } \\
\cline { 3 - 6 } & & Good & Absent & Drop-out & Total \\
\hline \multirow{3}{*}{$\begin{array}{l}\text { Alliance with } \\
\text { parents }\end{array}$} & Good & 38 & 4 & 1 & 43 \\
& Aartial & 17 & 12 & 1 & 30 \\
& Absent & 6 & 5 & 0 & 11 \\
& Total & 61 & 21 & 2 & 84 \\
\hline
\end{tabular}

Notes: $\chi^{2}(4)=12.17 ; P<0.05$.

a significant difference both in therapeutic compliance after eight months $\left(\chi^{2}(4)=12.17 ; P<0.05\right)$ and in the kind of clinical evolution $\left(\chi^{2}(4)=15.22 ; P<0.05\right)$ between groups of patients with different levels of alliance. From the point of view of frequency, we can say that in groups with better alliances there is a higher number of therapeutically compliant patients with improved health eight months later. We performed a nonparametric correlation analysis of these variables and we found a significant positive correlation both between alliance and positive therapeutic compliance (Spearman's rho $=0.33 ; P<0.05$ ) and between alliance and clinical evolution (Spearman's rho $=0.34$; $P<0.05)$.

We tried to verify if there was a significant relation between the clinical evolution of patients and their therapeutic compliance. We found a significant relation between clinical evolution and patient's compliance $\left(\chi^{2}(4)=42.02 ; P<0.05\right)$. This result represents a confirmation of the importance of the alliance. We actually found that patients whose parents build up a good alliance with the clinician exhibit a higher compliance; patients with a higher compliance are more likely to evolve positively.

We analyzed clinical evolution with respect to the different levels of alliance and split our sample into four categories on the basis of clinical diagnosis. Results confirm our hypothesis (the higher the alliance, the higher the probability of positive evolution) for two diseases, ie, emotional behavioral disease $\left(\chi^{2}(4)=10.29 ; P<0.05\right)$ and development disease $\left(\chi^{2}(4)=14.01 ; P<0.05\right)$; no significant results were found for anxiety disease $\left(\chi^{2}(4)=0.33 ; P>0.05\right)$, and mental disorder was not otherwise specified $\left(\chi^{2}(4)=\right.$ $2.22 ; P>0.05)$. These results can be partially explained by the insufficient number of subjects in the second two categories.

Finally, it is very interesting to note that there is no significant relation between patient participation and clinical evolution $\left(\chi^{2}(4)=3.92 ; P>0.05\right)$. This result indicates that 
Table 2 Frequencies table of the variable "Clinical Evolution" cross-tabled with the variable "Alliance with Parents"

\begin{tabular}{|c|c|c|c|c|c|}
\hline & & \multicolumn{4}{|c|}{ Clinical evolution } \\
\hline & & Improved & Unvaried & Worsen & Total \\
\hline & Good & 28 & 15 & 0 & 43 \\
\hline \multirow{3}{*}{$\begin{array}{l}\text { Alliance with } \\
\text { parents }\end{array}$} & Partial & 13 & 15 & 2 & 30 \\
\hline & Absent & 3 & 5 & 3 & II \\
\hline & Total & 44 & 35 & 5 & 84 \\
\hline
\end{tabular}

Notes: $\chi^{2}(4)=15.22 ; P<0.05$.

the clinican's alliance with parents is relevant for the good clinical evolution in the health of patients aged between 0 and 11 years. This variable seems to be more relevant than the patient's own participation in therapy.

\section{Discussion}

The results of this study confirm the value of communication between the parental couple and clinican to avoid the "sense of expropriation" during the inital interviews. ${ }^{6}$ Parents can see the therapist as an archaic, omnipotent and threatening parental figure ${ }^{7}$ or, more often, as an "adult able to be a better parent than they are" and so feel threatened. If these feelings are not dealt with and developed, they can lead to early interruption of treatment as soon as child's symptoms become less evident and the need to belittle the rival prevails., ${ }^{2,4}$ The relationship between child, clinician, and parental couple makes it possible to work through these feelings and experiences so that it becomes possible to establish quite a good relationship as a basis for a good therapeutic alliance with the child too.

With regard to the request for help, even though in most cases discomfort is reported by parents, sometimes requests for help have been driven by others (teachers, general practitioners, other clinicians, or social services). In these cases too, as Ferruzza ${ }^{3}$ pointed out, the request for consultation must become something that comes from parents in order to promote the creation of an essential therapeutic alliance between the clinican and the family based on the parents' sense of responsibility.

As a matter of fact, it may seem paradoxical, but parents must prepare themselves for the child's potential improvement because the change modifies their relationship with their child and because the change intimately modifies the relationship with their own interior child. ${ }^{8}$

Of patients in our sample, $66.7 \%$ came by referral, while $33.3 \%$ came spontaneously (parents' direct request). The mode of access in our sample does not seem to be statistically associated with other variables such as patient participation, therapeutic compliance, and clinical evolution.

Capozzi and Diomede ${ }^{9}$ underlined that diagnosis and therapy in developmental age are based on a multifactorial model which involves several more interlocutors (young patient, environment/family, and clinicians) with different instruments and techniques, and the necessary involvement of family in the diagnostic process ${ }^{10}$ through to the end of therapy.

Parents can be involved in different ways from the first meeting. Some specialists work only with the child and send parents to another colleague. Others consider continuous and frequent contact with parents to be fundamental. This depends on the one hand on the different schools of thought and theoretical models to which the clinician refers and on the other on the specific family situation.

A parallel space is reserved for parents in which their level of disfunctionality as a couple or as a family is taken into account and it forms part of a therapeutic alliance with them; this makes it possible to preserve compliance, ensuring a positive potential outcome by getting involved in the care of their child.

Sometimes parents of problematic children see themselves as failures and inadequate; they are full of guilt and they feel as if their identity as fathers and mothers were strongly threatened. This appears even more fundamental during moments of crisis such as when they ask for help. The psychodiagnostic and therapeutic intervention model we applied in the consulting rooms of our neuropsychiatric unit provides separate and parallel spaces for the child and the parental couple. We think this model of intervention promotes the creation of an appropriate alliance with parents. The latter, as highlighted by the results of this study, is relevant both for therapeutic compliance and therapy's effectiveness.

The analysis of our data with the Chi-squared test confirms our initial hypothesis about the correspondence of different levels of a clinician's alliance with parents with different levels of compliance and clinical evolution of health. Moreover, a nonparametric correlation analysis shows a positive correlation between collaboration and therapeutic compliance and between collaboration and outcome (the latter corresponding to clinical effectiveness).

Our results confirm Palacio-Espasa' ${ }^{11}$ view when he points out that the clinician's alliance with parents established during the diagnostic phase enables clinicians to better comprehend what the most appropriate solution for the child and his problems is, and consequently promotes an improvement in the clinical situation. ${ }^{12,13}$ 
To think of the care of a psychologically vulnerable child also means to evaluate the kind of help needed by his or her parents, and to offer them a space where they can deal with their emotional reactions towards the child's problems ${ }^{8}$ and their way of being parents..$^{14,15}$

In our sample, 16 patients who did not receive any recommendation to undergo therapy exhibited an evolutionary trend comparable to patients who were recommended some form of treatment. Once again, the decisive factor for patients' clinical evolution turned out to be the clinician's alliance with parents. The statistical analysis highlighted a significant difference in the clinical evolution of patients who were not recommended therapeutic treatment on the basis of parents' alliance as detected during the diagnostic process $\left(\chi^{2}(2)=8.00 ; P<0.05\right)$. Moreover, the correlation analysis with the use of Spearman's rho nonparametric test highlighted that increased collaboration corresponds to a higher probability of patients' improvements (Spearman's rho $=-0.695 ; P<0.05)$.

Therefore, we can confirm that even when the psychodiagnostic process does not include a structured therapy, counseling sessions can allow both parents and child to discover new meanings to their behavior and to establish a new and less disturbed relationship which enables the child to continue his or her physiological psychodevelopmental trend. In this case, parents can prolong the psychodiagnostic consultation's beneficial effects over time.

We actually found that patients whose parents build a good alliance with the clinician exhibited a higher compliance. Patients with a higher compliance have a much higher likelihood to have improved health $\left(\chi^{2}(2)=15.22 ; P<0.05\right) .{ }^{16,17}$ These results indicate that if, generally speaking, the therapeutic alliance can be seen as the therapy's keeper, more specifically a positive alliance with parents becomes the keeper of a good therapeutic relationship with the child. Just think of the fact that parents have to guarantee they will take the child to the sessions or the fact that their active participation in sessions is very important, and so is their helpfulness in filling out tests or in talking about themselves or about their family, in order to see the child in a dynamic and complex setting with all of his/her expressions of discomfort. ${ }^{18}$ A good clinical alliance with parents permits parents to evolve in parallel with their child's evolution.

The results of this study in relation to the importance of the alliance with parents during the diagnostic process demonstrate that the parental couple's participation in the comprehension process will prepare parents to adapt to the child's changes appropriately. So, it is possible to say that the factors that most influence the results of psychotherapy and outcome during developmental age is the family's ability to get involved, as well as the child's personal characteristics. ${ }^{19}$ In this respect, it must be mentioned that in our sample patients' participation during sessions did not influence clinical outcome (and therapy effectiveness) as much as the quality of the relationship between the clinician and parental couple.

\section{Conclusions}

Our results confirm the initial hypothesis about the importance of the alliance with parents as a factor that influences therapeutic compliance and therapy effectiveness. This suggests that the creation of good communication and alliance with the child's parents produces benefits both in terms of a response to parents' needs and as a response to the discomfort expressed by children.

Clearly, the creation of a good relationship with parents enables them to participate more actively in the comprehension of the therapeutic and evolutionary process of their child (in the case of structured therapy). ${ }^{20}$

Therefore, starting from the first interview with the child, parental influence makes its voice heard loudly. The possibility of creating a good alliance with the young patient depends on his or her ability to create positive relationships with the significant people (parents, friends, clinicians) in his or her personal history, therefore he or she can trust and rely on their relationship with the clinician.

Finally, on the assumption that establishing communication with the child is the fundamental aim of the "therapeutic consultation" - as it was called by Winnicott ${ }^{2}$ - it is obvious that the child's ability to engage in therapy is strongly influenced by the alliance established between clinician and parents. ${ }^{1}$

\section{Disclosures}

The authors report no conflicts of interest in this work.

\section{References}

1. Marcelli D. Enfance et Psychopathologie. Paris, France: Masson; 1996.

2. Winnicott DW. The Maturation Processes and the Facilitating Environment. New York, NY: International Universities Press; 1965.

3. Ferruzza E. Il lavoro psicoterapeutico con genitori e figli nel tempo. In: Pierri M, editor. Padova, Italy: Patron; 1999. pp. 157-160.

4. Mancini G. L’alleanza terapeutica come custode della psicoterapia. 2003. Available from: http://www.cipspsia.it/allegati/ Tesina-Alleanza-Terapeutica-MANCINI.pdf. Accessed on August 10, 2009

5. World Health Organization. ICD 10, International Statistical Classification of Diseases and Related Health Problems. 10th Ed. Arlington, VA: American Psychiatry Publishing; 1992. 
6. Fava Vizziello G, Bet M, Sandonà G. Il bambino che regalò un arcobaleno. Torino, Italy: Boringhieri Bollati; 1990.

7. Mazet P, Sibertin Blanc D. L'examen psychiatrique de l'enfant. Encycl Med Chir Paris Psychiatrie. 1982;37(102):C10, 2.

8. Rocco P. Considerazioni sul setting della terapia analitica. Informazione in psicologia psicoterapia psichiatria. 1996;26:24-31.

9. Capozzi F, Diomede L. La cura dei disturbi di sviluppo: un buon incontro tra riabilitazione e psicoterapia. Psichiatria dell'Infanzia e dell'Adolescenza. 2005;72:181-189.

10. Fabrizi A, Santacroce M, D’Ardia C, Iacovelli L, Totonelli L. Diagnosi dei disturbi dello sviluppo in età precoce: riflessioni teorico cliniche sulle risposte genitoriale. Psichiatria dell'Infanzia e dell'Adolescenza. 2005;73:199-212.

11. Palacio-Espasa F. Psicoterapia con i bambini. Milano, Italy: Raffaello Cortina Editore; 1995.

12. Nock MK, Ferriter C. Parent management of attendance and adherence in child and adolescent therapy: A conceptual and empirical review. Clin Child Fam Psychol Rev. 2005;8:149-166.

13. Shuman AL, Shapiro JP. The effects of preparing parents for child psychotherapy on accuracy of expectations and treatment attendance. Community Ment Health J. 2002;38:3-16.
14. Karver M, Handelsman J, Fields S, Bickman L. Meta-analysis of therapeutic relationship variables in youth and family therapy: The evidence for different relationship variables in the child and adolescent treatment outcome literature. Clin Psychol Rev. 2006;26:50-65.

15. Martin D, Graske J, Davis M. Relation of the therapeutic alliance with outcome and other variables: A meta-analytic review. J Consult Clin Psychol. 2000;68:438-450.

16. Hersoug AG, Høglend P, Monsen JT, Havik OE. Quality of working alliance in psychotherapy: therapist variables and patient/therapist similarity as predictors. J Psychother Pract Res. 2001;10(4):205-216.

17. Ackerman S, Hilsenroth M, Knowles E. Ratings of therapist dynamic activities and alliance early and late in psychotherapy. Psychotherapy: Theory Research Practice Training. 2005;42:225-231.

18. Gaston L. The concept of the alliance and its role in psychotherapy: theoretical and empirical considerations. Psychotherapy. 2004;27: $143-153$.

19. Gaggero R, Orsini S. Psicoterapia infantile: dai modelli teorici alla pratica clinica. Psichiatria dell'Infanzia e dell'Adolescenza. 2002;69:531-540.

20. Boatti L. Gruppi di bambini, gruppi di genitori. Psichiatria dell' 'infanzia e dell'adolescenza. 2002;69:507-520.
Neuropsychiatric Disease and Treatment

\section{Publish your work in this journal}

Neuropsychiatric Disease and Treatment is an international, peerreviewed journal of clinical therapeutics and pharmacology focusing on concise rapid reporting of clinical or pre-clinical studies on a range of neuropsychiatric and neurological disorders. This journal is indexed on PubMed Central, the 'PsycINFO' database and CAS, and is the official
Submit your manuscript here: http://www.dovepress.com/neuropsychiatric-disease-and-treatment-journal

\section{Dovepress}

journal of The International Neuropsychiatric Association (INA). The manuscript management system is completely online and includes a very quick and fair peer-review system, which is all easy to use. Visit $\mathrm{http}: / / \mathrm{www}$.dovepress.com/testimonials.php to read real quotes from published authors. 